\title{
'Running on empty': understanding more about the concerns around burnout in a cohort of trainee doctors, and the value of reflective practice as an intervention
}

\author{
Authors: Esme Ingram, ${ }^{\mathrm{A}}$ Louise Restrick ${ }^{\mathrm{A}}$ and Sarah Lunn ${ }^{\mathrm{A}}$
}

\section{Introduction}

The impact and risks of burnout for health professionals, patients and the NHS are increasingly recognised as a major issue for our healthcare system. ${ }^{1,2} 28 \%$ of doctors currently report feeling unable to cope with their workload at least weekly and $12 \%$ took leave due to stress. ${ }^{2}$

While the issue of working in an under-resourced, under-staffed system needs to be systematically addressed, reflective practice (RP) is an evidence-based approach that can increase wellbeing. ${ }^{3}$ As an acute trust with an integrated clinical psychology team, a number of our multidisciplinary teams already use RP to support staff in their work. ${ }^{4}$

The aim of this study was to explore concerns regarding burnout and wellbeing in a cohort of trainee doctors in one acute trust and to design, pilot and evaluate a clinical psychologist reflective practice facilitated programme for medical trainees, focusing on wellbeing.

\section{Materials and methods}

Trainees working in one acute trust were asked to complete a survey (1-10 scaling) concerning wellbeing and attitude to RP. An $\mathrm{RP}$ wellbeing-focused programme, comprising three 1-hour sessions held every 2 months, was designed, facilitated and piloted by a clinical psychologist. Core medical trainees and specialist medical registrars $(n=24)$ were invited to attend sessions during a weekly lunchtime teaching slot. Feedback was collected during and after each RP session.

\section{Results and discussion}

$45 / 161$ (28\%) trainee doctors completed the survey. The majority were very concerned about the impact of their work demands on their wellbeing (mean 7.7/10; range 1-10) and welcomed the offer of supervised RP sessions (mean 7.2/10); $88 \%$ requested as monthly sessions.

Attendance at all three RP sessions was the same, or more than, other timed teaching offered to the same cohort of medical trainees. RP sessions were highly valued with mean helpfulness/importance

Authors: ${ }^{A}$ Whittington Health NHS Trust

\begin{tabular}{|c|c|}
\hline Themes on risk of burnout & Trainee quotes \\
\hline The problem with 'resilience' & $\begin{array}{l}\text { 'Resilience' implies we should be able to cope with } \\
\text { everything.' 'I hate the word "resilient". It leaves me } \\
\text { feeling like a failure when I'm struggling at work.' } \\
\text { 'Being told to be resilient is insulting!' }\end{array}$ \\
\hline $\begin{array}{l}\text { Resources versus demands: mismatch between the } \\
\text { resources available and the demands on us }\end{array}$ & $\begin{array}{l}\text { 'How to think about time management in a useful } \\
\text { way - rather than just being something to berate } \\
\text { yourself ... that you are finding the workload too } \\
\text { great.' 'Want to be able to process frustration about } \\
\text { systems and colleagues in productive ways.' 'Want } \\
\text { to try and minimise a culture of people often } \\
\text { becoming very critical.' }\end{array}$ \\
\hline $\begin{array}{l}\text { Emotional impact: distress and helplessness of } \\
\text { witnessing the suffering of patients }\end{array}$ & $\begin{array}{l}\text { 'Last year I was involved in an unexpected death } \\
\text { which is something I found incredibly difficult to } \\
\text { manage ... when I talked to my peers it turned out } \\
\text { that nearly all of them had been involved in equally } \\
\text { difficult and challenging situations and wished that } \\
\text { they had been able to talk to someone.' }\end{array}$ \\
\hline $\begin{array}{l}\text { Feeling out of my depth: the difficulty of not } \\
\text { knowing what to do }\end{array}$ & $\begin{array}{l}\text { 'The sensation of feeling completely overwhelmed } \\
\text { by either how much you have left to do or by not } \\
\text { knowing how to do something, and then suddenly } \\
\text { freezing and not being able to focus or carry on with } \\
\text { the task in hand or even the simpler things, the } \\
\text { things you do know how to do.' 'Trying to balance } \\
\text { feeling completely panicked and wanting to cry with } \\
\text { the expectation that you should just be able to get } \\
\text { on and that someone's care is dependent on you } \\
\text { being able to manage and know what to do.' }\end{array}$ \\
\hline $\begin{array}{l}\text { Feelings of guilt between peers: not wanting to let } \\
\text { others down by taking time off or leaving on time }\end{array}$ & $\begin{array}{l}\text { 'How to know when it is OK to leave work on time } \\
\text { when the workload is never ending.' }\end{array}$ \\
\hline $\begin{array}{l}\text { Compromised work-life balance and difficulty } \\
\text { switching off }\end{array}$ & $\begin{array}{l}\text { I could really do with thinking about how I can } \\
\text { better manage the uncertainty and difficulties I find } \\
\text { at work, which will then hopefully enable me to } \\
\text { switch off more at home.' }\end{array}$ \\
\hline Culture of silence & $\begin{array}{l}\text { 'As a profession we are terrible at admitting we are } \\
\text { struggling.' }\end{array}$ \\
\hline
\end{tabular}

Fig 1. Themes on risk of burnout from trainee survey and reflective practice sessions with medical trainee doctors in one acute trust.

scores of $9.5 / 10$ ( $n=21$; range $9-10)$. When asked to what extent they felt they would benefit from further RP sessions, the mean score from all attendees was $8.3 / 10(n=21)$.

Key qualitative survey findings and themes around risk of burnout identified in RP sessions are shown in Fig 1, and the impact of RP and assets identified during RP sessions are described in Fig 2.

\section{Conclusion}

Concern about burnout was widespread in this cohort of trainee doctors working in an acute trust. There have been urgent calls at a national level to address workforce wellbeing and the impact of 'running on empty'.,2,5,6 While it is well-recognised that system factors play a significant role in the development of burnout, and 


\begin{tabular}{|l|l|}
\hline Themes on value of reflective practice & Trainee quotes \\
\hline Cathartic outlet in order to 'move on' & $\begin{array}{l}\text { '...the space to express concerns.' 'A forum to let go } \\
\text { of this.' }\end{array}$ \\
\hline $\begin{array}{l}\text { Moving from feeling alone to a sense of shared } \\
\text { struggle }\end{array}$ & $\begin{array}{l}\text { 'Feeling that you're not alone.' 'It's reassuring } \\
\text { knowing I'm not the only one.' 'It's good to hear } \\
\text { from others having similar experiences.' 'We are all } \\
\text { in this together mentality.' }\end{array}$ \\
\hline Normalising difficulty & $\begin{array}{l}\text { 'It's normal to be stressed about things.' 'This } \\
\text { normalises hard situations.' }\end{array}$ \\
\hline A safe supportive reflective space & $\begin{array}{l}\text { II feel more supported at work.' 'Was nice to reflect } \\
\text { and discuss challenges.' 'These sessions have } \\
\text { become a sanctuary in themselves.' }\end{array}$ \\
\hline $\begin{array}{l}\text { Expanding own ways of coping and sharing } \\
\text { strategies }\end{array}$ & $\begin{array}{l}\text { 'A greater sense of headspace when working busy } \\
\text { jobs.' 'Allow me to look at the bigger picture, as well } \\
\text { as boost morale.' I particularly enjoyed the links } \\
\text { between sessions encouraging us to develop our } \\
\text { own strategies and discussing how that has gone.' 'It } \\
\text { has already changed the way I think about things ... } \\
\text { and I've passed this on to a colleague.' }\end{array}$ \\
\hline Reconnecting with what is meaningful about work & $\begin{array}{l}\text { '...reinforced what I value about my job and made } \\
\text { me feel better about myself.' }\end{array}$ \\
\hline
\end{tabular}

Fig 2. Value of reflective practice sessions: themes on impact of sessions and identified assets from reflective practice sessions with medical trainee doctors in one acute trust.

under-staffing needs to be addressed at a national level, individual factors are also important., ${ }^{1,2}$

Following feedback that reflective practice sessions would be welcomed, we piloted a psychologist-led wellbeing programme. This was well-attended and highly valued by trainees. Sessions were described as enabling a 'safe-space' for trainees to talk about themes that contribute to risk of burnout including underresourcing, impact of 'feeling alone', and of 'not talking' but also importantly, as developing a community of support that enabled discussion of shared challenges and coping initiatives.
As a result of this successful pilot, clinical psychologist reflective practice facilitated sessions are now being provided on a monthly basis for medical trainees in our trust.

\section{Conflicts of interest}

None declared.

\section{References}

1 British Medical Association. Mental health and wellbeing in the medical profession. BMA, 2019. www.bma.org.uk/collective-voice/ policy-and-research/education-training-and-workforce/supportingthe-mental-health-of-doctors-in-the-workforce [Accessed 29 October 2019].

2 General Medical Council. The state of medical education and practice in the UK: The workforce report 2019. GMC, 2019. www. gmc-uk.org/-/media/documents/the-state-of-medical-educationand-practice-in-the-uk-workforce-report_pdf-80449007.pdf [Accessed 29 October 2019].

3 Heneghan C, Wright J, Watson G. Clinical psychologists' experiences of reflective staff groups in inpatient psychiatric settings: A mixed methods study. Clin Psychol Psychother 2014;21:324-40.

4 Stern M, Saunders H, Davidson C. Embedding and improving confidence to practice ADP skills through regular reflective practice in a multidisciplinary community respiratory team. In: Conference on educating for patient-centred care (UCL Partners), London, UK.

5 Medical Protection. Urgent action needed to tackle burnout endemic in healthcare. Medical Protection, 2019. www. medicalprotection.org/uk/articles/urgent-action-needed-to-tackleburnout-endemic-in-healthcare [Accessed 29 October 2019].

6 Health Education England. NHS staff and learners' mental wellbeing commission: February 2019. HEE, 2019. www.hee.nhs.uk/ sites/default/files/documents/NHS \% 20 \% 28HEE \% 29\% 20- \% 20 Mental \% 20Wellbeing \% 20Commission \% 20Report \% 20\% 28Summary \% 29.pdf [Accessed 29 October 2019]. 